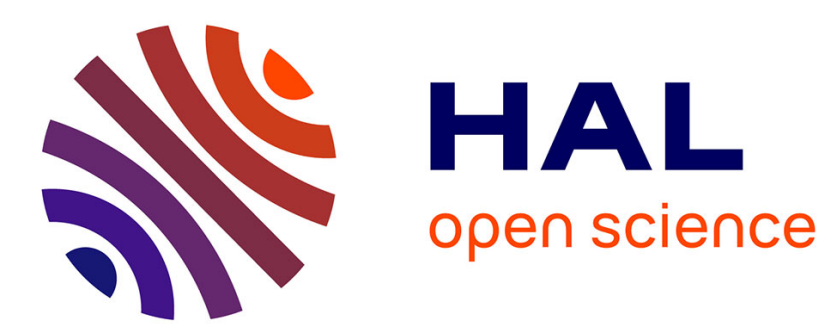

\title{
Design, manufacturing and characterization of printed circuit board embedded inductors for power applications
}

Rémy Caillaud, Cyril Buttay, Roberto Mrad, Johan Le Lesle, Florent Morel, Nicolas Degrenne, Stefan Mollov, Christian Martin

\section{- To cite this version:}

Rémy Caillaud, Cyril Buttay, Roberto Mrad, Johan Le Lesle, Florent Morel, et al.. Design, manufacturing and characterization of printed circuit board embedded inductors for power applications. 2018 IEEE ICIT, Feb 2018, Lyon, France. 10.1109/ICIT.2018.8352262 hal-01736336

\section{HAL Id: hal-01736336 https://hal.science/hal-01736336}

Submitted on 16 Mar 2018

HAL is a multi-disciplinary open access archive for the deposit and dissemination of scientific research documents, whether they are published or not. The documents may come from teaching and research institutions in France or abroad, or from public or private research centers.
L'archive ouverte pluridisciplinaire HAL, est destinée au dépôt et à la diffusion de documents scientifiques de niveau recherche, publiés ou non, émanant des établissements d'enseignement et de recherche français ou étrangers, des laboratoires publics ou privés. 


\title{
Design, manufacturing and characterization of printed circuit board embedded inductors for power applications
}

\author{
Rémy CAILLAUD ${ }^{1,2}$, Cyril BUTTAY ${ }^{2}$, Roberto MRAD ${ }^{1}$, Johan LE LESLÉ ${ }^{1,3}$, Florent MOREL ${ }^{3}$, Nicolas \\ DEGRENNE $^{1}$, Stefan MOLLOV ${ }^{1}$ and Christian MARTIN ${ }^{4}$ \\ ${ }^{1}$ Mitsubishi Electric R\&D Centre Europe, 1 Allée de Beaulieu, 35708 Rennes, France \\ ${ }^{2}$ Université de Lyon, INSA de Lyon, UMR CNRS 5005, F-69621, France \\ ${ }^{3}$ Université de Lyon, Ecole Centrale de Lyon, UMR CNRS 5005, F-69134, France \\ ${ }^{4}$ Université de Lyon, Université Lyon 1, UMR CNRS 5005, F-69621, France
}

\begin{abstract}
The Printed-Circuit-Board (PCB) technology is attractive for power electronic systems as it offers a low manufacturing cost for mass production. Power inductors are large and complex to manufacture, because they usually are custom components which must be wound individually. Inductors based on PCB technology can reduce the complexity and cost while using a wasted space (the thickness of said PCB).

In this paper, a procedure to design such inductors is summarized, with a focus on inductors intended to be implemented in converters in the 100-1000 $\mathrm{W}$ range. The main contribution of this paper is the description of the manufacturing process : the inductors use PCB to host their magnetic core while their winding is made by patterning the $\mathrm{PCB}$ copper layers and using copper vias. In addition, new experimental results are presented : the prototypes are electrically characterized, and the results are discussed to present the advantages and drawbacks of this technology, as well as the remaining open questions.
\end{abstract}

\section{INTRODUCTION}

Although it is a recent technology, embedding of power electronic components in Printed Circuit Board (PCB) has attracted interest from the industry, with products already available on the market [1]. This technology enables more integrated converters, with a single, consistent manufacturing process. PCBs present a low manufacturing cost for mass production. While a large part of the research effort is focused on embedding active devices, the passive components represent a large share $(20 \%)$ of a converter volume (on-par with its cooling system and empty spaces) [2]. Improving the integration level of passive components is therefore crucial to further reduce the converter volume.

Among the passive components, magnetic components are attractive candidates for embedding technologies because they are generally custom components. Planar components (with winding formed on a PCB and low-profile, E-shape magnetic cores clamped around) partially address these issues but fully PCB embedded structures can go further as described in [3], but so far, most of the research is focused on low-power (1$100 \mathrm{~W})$ components [4], [5]. [6] shows that little improvements are to be expected from the magnetic materials in the foreseeable future. Most of the gain should come from a better use of the existing materials. This can be done using embedded solid cores as in [4]. Such technique is already implemented in low power commercial (e.g. NXE2 from Murata), but must be extended to higher power levels.

Because solid cores (ferrite, iron powder, etc.) are brittle, the embedding process has to be well controlled to avoid cracking the magnetic core, creating unwanted air-gap and changing the electrical behavior of the magnetic components. In order to keep a simple process, more compliant materials also have been studied, such as organic pastes with a ferrite load [7], direct embedding of ferrite powder [8], or use of thin-layers (tens of microns) of permalloys or amorphous materials [9]. These materials constitute an alternative but their performances tend to be lower than those of solid cores. With the aim to obtain the best performance in a reasonable volume, this paper will focus on the embedding of large (outer diameters of up to $50 \mathrm{~mm}$ ) solid cores with or without air-gap.

In [10], we presented the method used to design inductors embedded in PCB. This paper presents new results focused on the manufacturing process of such inductors, as well as on their testing. We firstly introduce the inductor design procedure which leads to the choice of toroidal embedded inductors for our converter. We then present the manufacturing process used for the production of our PCB-embedded inductor prototypes from the magnetic core machining to obtain the required thickness to the last step of the PCB process. Lastly, prototypes characterizations using impedance analyzer are presented and then discussed.

\section{MAGNETIC DESIGN}

The inductor structure chosen for our converter is referred to as "toroidal embedded". It uses PCB with a cavity to host a toroidal magnetic core. The winding is manufactured around the magnetic core by patterning the PCB copper layers and placing vias for the interconnections. The structure is presented in Fig. 1.

An automated design procedure was set-up to compare the toroidal embedded structure with more classical structures such as planar or wire-wound cores [10]. This design procedure allows to investigate many parameters such as magnetic 
materials or core geometries, and automatically checks that the configuration meets the PCB design rules. For a chosen structure, material and core size, a program calculates the number of turns required to achieve the desired inductance value. Then, this configuration is checked for saturation of the magnetic core. For ferrite materials, an air-gap is designed to prevent saturation, while for iron powder materials (which have a distributed air gap) the configuration which lead to saturation are simply discarded.

For all acceptable configurations, the inductor losses are calculated using the improved Generalized Steinmetz Equation (iGSE) for core losses and FEM simulation for copper losses (to account for skin and proximity effects). A 2D thermal FEM simulation is then run to ensure the inductor remains below a fixed temperature limit $\left(100{ }^{\circ} \mathrm{C}\right)$. All configurations which result in higher temperature are discarded. The best inductor is defined by the best trade-off between losses and box volume [10]. Finally, the program generates an script, which is run in the PCB design software (Altium) to automatically produce the Gerber files for the selected inductor.

It was found that the toroidal embedded structure presents the best trade-off between losses and box volume due to its better cooling capability (its flat shape results in large surfaces for heat exchange). This structure was chosen to be used for the EMI differential mode (DM) filter inductor in a Power Factor Corrector (PFC) application. The corresponding design parameters are listed in table I.

Table I: Prototypes parameters. Two inductors designs are considered: a "test' inductor, used for technology set-up, and a "filter" inductor, for the application described in section II.

\begin{tabular}{l|l|l}
\hline Properties & Test inductor & EMI Filter inductor \\
\hline \hline Core thickness & $3 \mathrm{~mm}$ & $3 \mathrm{~mm}$ \\
\hline Copper thickness & $105 \mu \mathrm{m}$ & $105 \mu \mathrm{m}$ \\
\hline Via hole drilling diameter & $0.6 \mathrm{~mm}$ & $0.6 \mathrm{~mm}$ \\
\hline Magnetic material & MPP200 & Ferrite N87 \\
\hline Outer Diameter & $27.7 \mathrm{~mm}$ & $50 \mathrm{~mm}$ \\
\hline Inner Diameter & $14.1 \mathrm{~mm}$ & $30 \mathrm{~mm}$ \\
\hline Number of turns & 18 & 16 \\
\hline Air-gap & - & $1.3 \mathrm{~mm}$ \\
\hline$\mu_{r} / \mu_{e f f}$ & 200 & 96 \\
\hline $\mathrm{Expected} \mathrm{Inductance}_{\mathrm{R}_{D C}}^{18.1 \mu \mathrm{H}}$ & $7.95 \mu \mathrm{H}$ \\
\hline $\mathrm{I}_{M a x}$ & $156 \mathrm{~m} \Omega$ & $35 \mathrm{~m} \Omega$ \\
\hline & $5 \mathrm{~A}$ & $21.2 \mathrm{~A}$ \\
\hline
\end{tabular}

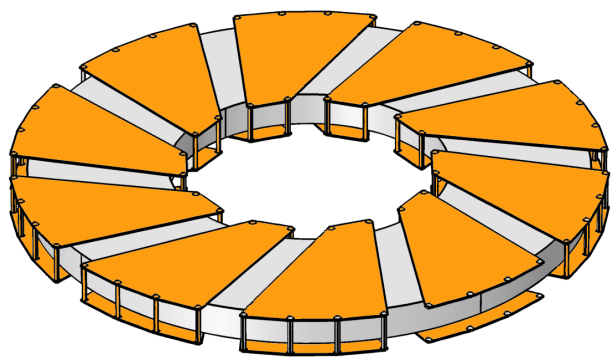

Fig. 1: 3D view of the toroidal embedded structure. The PCB material is not represented.

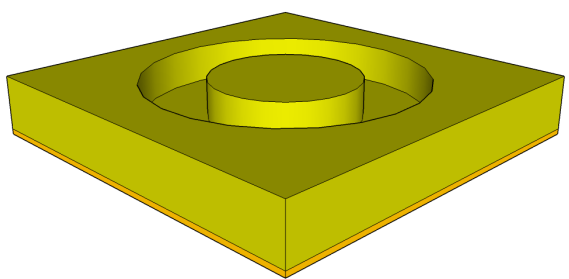

(a)

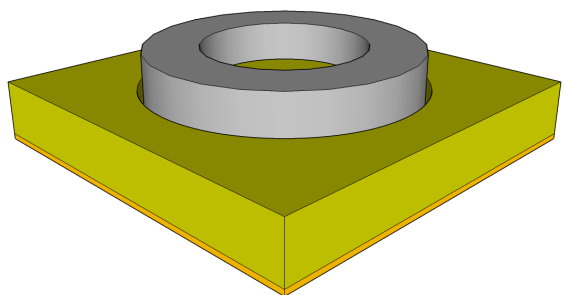

(b)

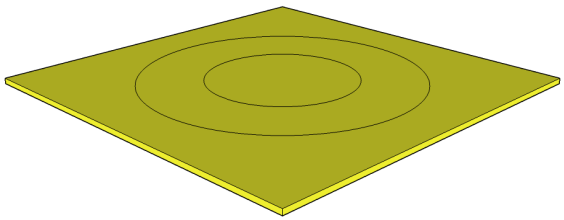

(c)

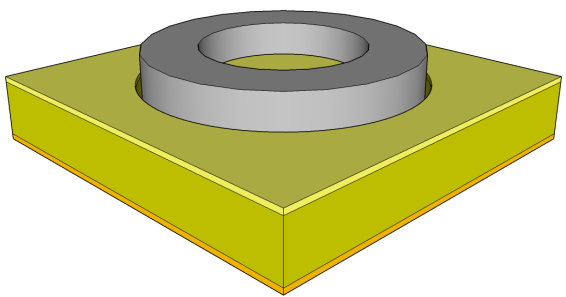

(d)

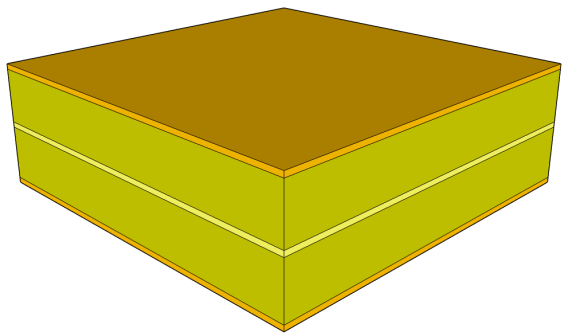

(e)

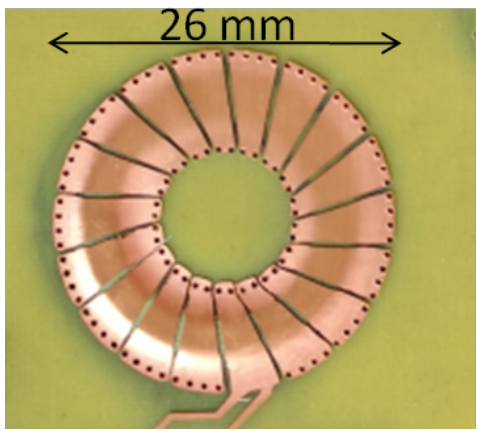

(f)

Fig. 2: Process flow for the fabrication of a PCB embedded inductor. 


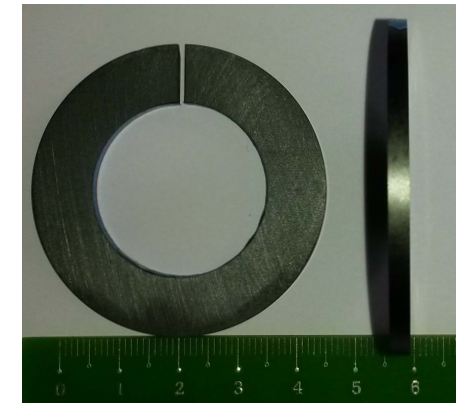

Fig. 3: MnZn ferrite (N87 from EPCOS) core with a single air-gap (1.9 mm), prepared by slicing a larger magnetic toroid, and cutting the air-gap using a wire saw.

\section{MANUFACTURING}

The manufacturing approach developed in this paper is summarized in Fig. 2. A cavity is formed by machining two single-face PCB laminates (a). Then the magnetic core is placed in the cavity of one of the laminates (b). A sheet of stage-B epoxy-glass composite is laser-cut with the outline of the magnetic core (c), and placed on the stack (d). The second PCB laminate is finally placed on top (e), and a lamination (temperature/pressure) cycle is performed to form a solid assembly. The winding is then formed using the standard PCB techniques such as copper etching and via electroplating (f).

For our prototypes two magnetic materials were used. The first material is a Ni-Fe-Mo powder core (MPP200, Magnetics). The second material is a MnZn ferrite (N87, EPCOS). The MPP200 toroidal core is embedded without any air-gap on the contrary of the N87 one. As decribed in table I, the desired thickness for the magnetic cores is $3 \mathrm{~mm}$. This core thickness results in a PCB close to the maximum thickness that many PCB manufacturers can process (here $3.2 \mathrm{~mm}$ ).

Unfortunately, it was not possible to purchase magnetic cores with the exact dimensions listed in table I. While magnetic tores were found with suitable inner and outer diameters, they all were much thicker than required. As a consequence, the first actual manufacturing step was to slice a thick magnetic core to produce $3 \mathrm{~mm}$-thick parts. This was performed using a Struers Discotom 100, equiped with a diamond blade (Struers MOD31). Then, when required, an air-gap is cut using a wire saw (3241 model, Well) with a diamond wire of 300 microns diameter. A MnZn ferrite core with is presented in Fig. 3 after this preparation, and prior to the embedding process described in Fig. 2.

After the magnetic cores have been prepared, the actual embedding process can be performed:

a) $1.6 \mathrm{~mm}$ thick, single face PCB laminates $(370 \mathrm{HR}$ material, Isola group) are machined using a $\mathrm{CNC}$ router (Charlyrobot 4U). Some clearance (a few 100s of microns) is required in the cavity depth to ensure the magnetic core will fit, and that it will not be pressed during the lamination cycle. This clearance is also required to account for planarity issues during the machining of the laminates. The maximum cavity thickness is defined

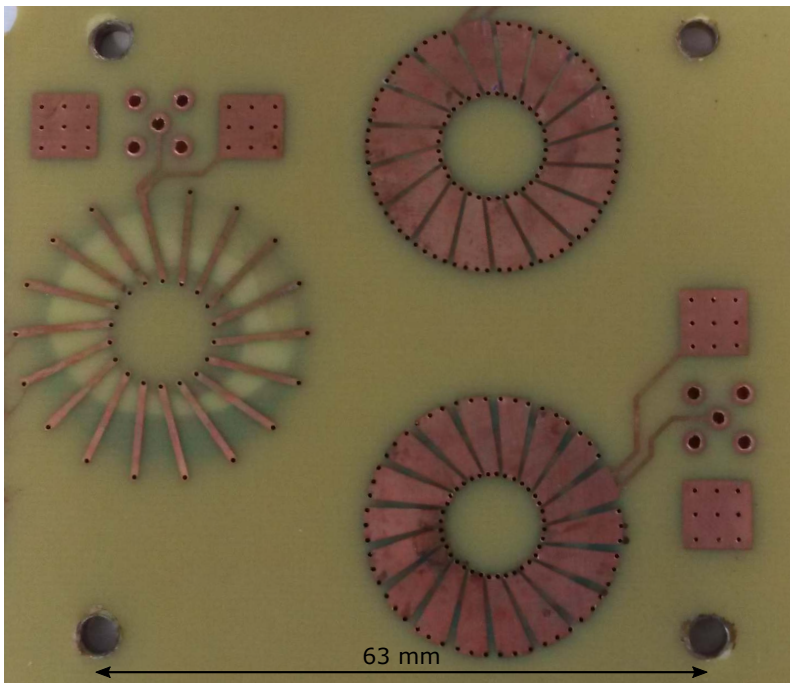

Fig. 4: Three embedded inductors processed simultaneously. The leftmost inductor is the discussed test inductor.

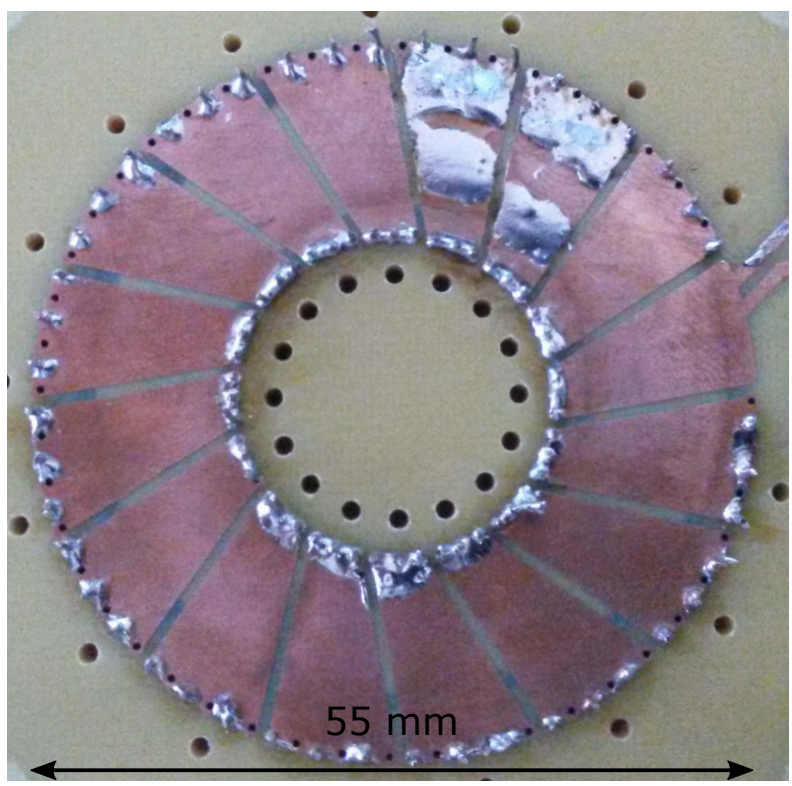

Fig. 5: EMI differential mode filter inductor.

by the isolation required between the winding (copper tracks) and the magnetic core.

b) The magnetic core is placed inside the cavity manually.

c) A prepreg sheet (Isola PCL370 HR 1080, $\mathrm{Tg}=180{ }^{\circ} \mathrm{C}$ ) is cut using a CO2 laser (Gravograph).

d) This sheet is placed on top of the PCB laminate. The center part is positioned manually in the interior of the magnetic core.

e) A second machined PCB laminate is placed on top of the stack to fully encapsulate the magnetic core. Sheets of release film (Pacolon HT2000) are placed under and over the PCB stack. Metal plates and alignment pins (which register with holes drilled in the PCB laminates) are used to maintain the assembly. The latter is placed in a heating press (Specac Atlas) for the PCB lamination cycle. The 


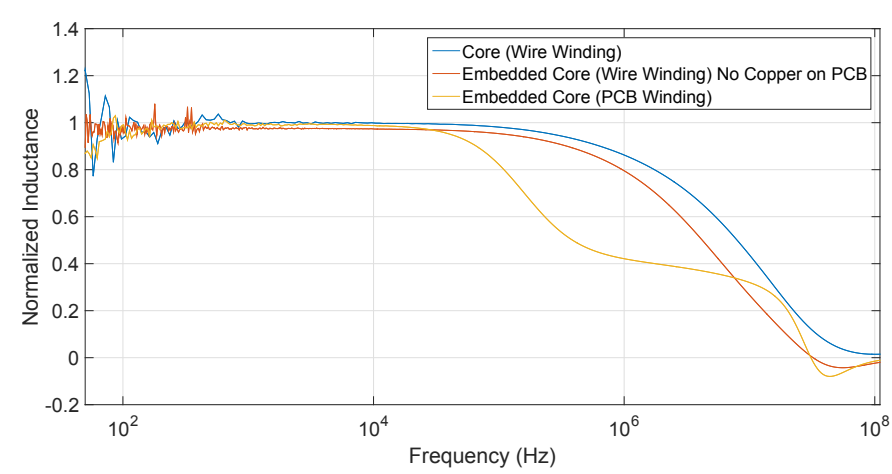

Fig. 6: Electrical characterization of the test inductor in the following configurations: before embedding process (with wire winding), after embedding process in a blank PCB (with wire winding, no copper on the PCB), and after the full embedding process (with PCB winding).

temperature is increased at a rate of $6{ }^{\circ} \mathrm{C} / \mathrm{min}$, up to $195{ }^{\circ} \mathrm{C}$ and it is maintained at this level for 90 minutes. The laminating pressure is 10 bar at the beginning and is then increased up to 20 bar once the temperature exceeds $100{ }^{\circ} \mathrm{C}$. At the end of this cycle, the assembly forms a unique, solid part.

f) Via holes (used to form the winding) are drilled in the PCB laminate using a CNC drill (Bungard CCD/2/ATC). The holes are plated with copper, using regular $\mathrm{PCB}$ chemistry (Bungard, using a Compacta plating station from the same manufacturer). Finally, the copper layers are selectively masked with a photosensitive dry film (Dupont Riston), according to the Gerber files generated by the design program, and patterned using ferric chloride.

Photographs of the various inductors produced using this process are given in Fig. 2(f), 4 and 5.

\section{Characterization}

The data presented here was acquired using an impedance analyzer (Keysight E4294A) with a 42941A probe. A SMA connector is soldered on the PCB for easy and reliable connection with the probe.

The electrical characterization of the test inductor is presented in Fig. 6. Three configurations were investigated: a simple magnetic core with wire winding (to make sure the core properties were not affected by the slicing process); the magnetic core embedded in a blank PCB (no copper), also using wire winding (to measure the effect of embedding); and the magnetic core embedded in a PCB with printed winding (the final version). As a different number of turns was used in the three cases, Fig. 6 presents the normalized inductance value as a function of the frequency. For the embedded test inductor using PCB winding, the low frequency inductance value is $17.6 \mu \mathrm{H}$ corresponding to the expected inductance $18.1 \mu \mathrm{H}$.

A micro-section of the test inductor, realized with a scanning electron microscope (Vega 3, Tescan), is presented in Fig. 7. This micro-section shows the magnetic core inside the cavity, with $\approx 400 \mu \mathrm{m}$ clearance between the core and the top of the cavity. No damage is noticeable on the core, except

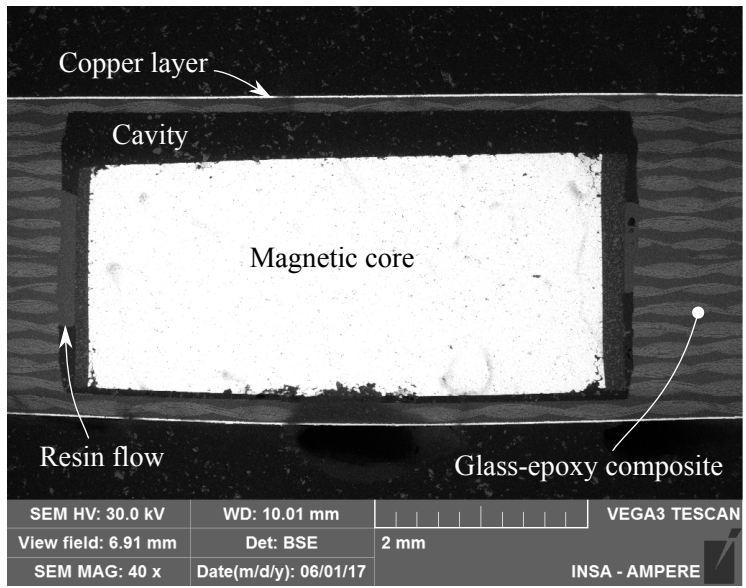

Fig. 7: Micro-section of the test inductor. Core is maintained inside the cavity at the middle by the prepreg sheet resine. The vias winding are not shown. The barrel shape is an artefact caused by using the microscope at low magnification. The outer surfaces of the sample are actually flat.

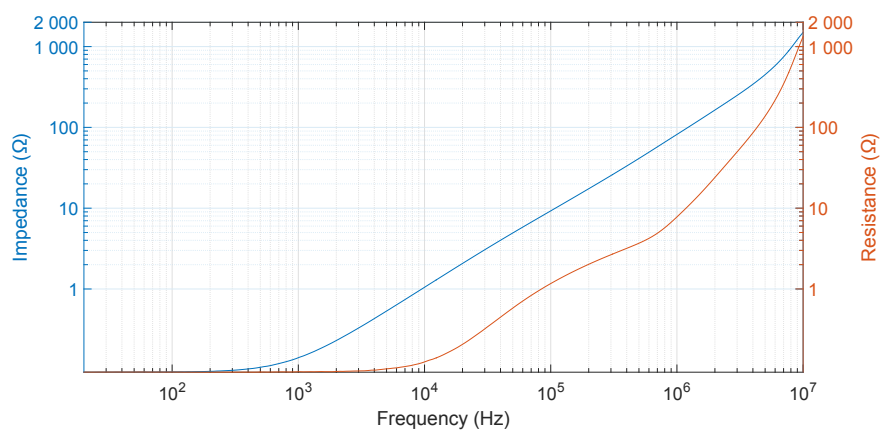

(a)

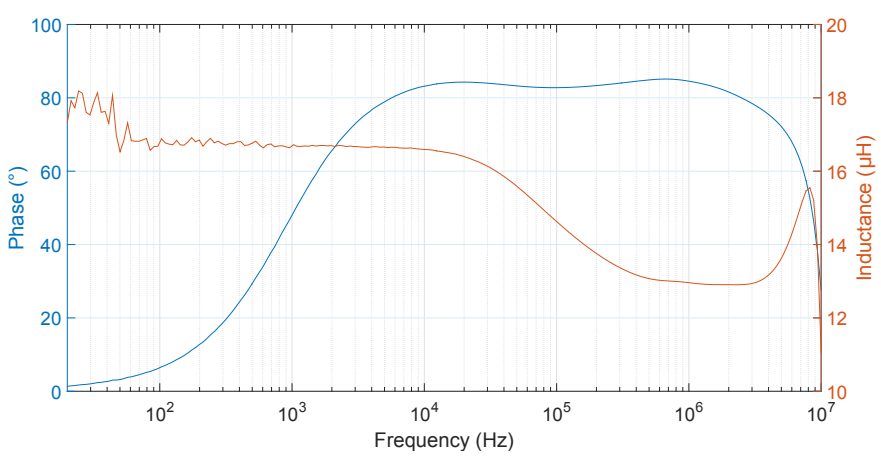

(b)

Fig. 8: Electrical characterization of Differential Mode inductor using N87 ferrite with a single air-gap (a) Impedance and resistance (b) Phase and inductance.

some chipping on the edges (which might have been caused during the preparation of the micro-section). Some of the resin flowed in the cavity during the lamination and maintains the magnetic core. The rest of the cavity remains empty.

The electrical characterization of the EMI DM Filter inductor is presented in Fig. 8 for the magnetic core embedded with a PCB winding (PCB copper tracks and vias). The impedance and resistance are traced as a function of the frequency in Fig. 8a. The phase and inductance are plotted as function of the frequency in Fig. 8b. The impedance and resistance are traced 
using a logarithmic scale to show their dramatic increase at relatively low frequency (tens of $\mathrm{kHz}$ ). For this inductor, the inductance value at low frequency is $16.7 \mu \mathrm{H}$.

\section{DISCUSSION}

As seen in the micro-section in Fig. 7, the embedding process is well controlled, and offers sufficient clearance to avoid stress on the brittle magnetic core during the lamination process. Even with the reduction in thickness of the prepreg layers (due to resin creep), the cavity remains taller than the magnetic core. The small amount of resin which flows out of the prepreg layers is not sufficient to fill the cavity, but offers satisfying bonding to prevent the magnetic core from moving. Therefore, it is not expected that the magnetic core behaviour is affected by the embedding process.

The inductance shows a good behavior (constant inductance value) for all samples in the low frequency range (up to a few tens of $\mathrm{kHz}$ ). For Ni-Fe-Mo powder core (test inductor), the inductance value in low frequency is $17.6 \mu \mathrm{H}$ for a calculated value of $18.1 \mu \mathrm{H}$. The little difference can be explained by a poor control of the magnetic core thickness (this was our first prototype). Further magnetic cores were sliced with a dedicated fixture, resulting in much better thickness control. For the MnZn core (EMI filter DM inductor), the inductance value in low frequency is $16.7 \mu \mathrm{H}$ for a calculated by the design script and expected value of $7.95 \mu \mathrm{H}$. This is a much larger error which is due to the fringing effect around the air gap. In the design script, the section of the air-gap is considered identical to that of the magnetic core. But with an air-gap length of $1.3 \mathrm{~mm}$ for a core thickness of $3 \mathrm{~mm}$, this assumption no longer holds true: the aspect ratio between the air-gap length and the core thickness is not negligible, resulting in a much larger equivalent section of the air-gap. The design procedure has to be modified to take into account the influence of the fringing effect on the reluctance of the air-gap [11].

A second issue is the inductance behavior at higher frequency. Above a few tens of $\mathrm{kHz}$, the inductance value decreases and the serial resistance value increases strongly. This is not acceptable, as these inductors were designed to be used in a converter with a switching frequency of $180 \mathrm{kHz}$. This behavior is not due to the core machining or the embedding process, since the non-embedded core or the embedded core with classic wire winding does not show this behavior (Fig. 6).

A second possible cause is the capacitance between PCB winding and the core, which is larger than with a wirewound inductor. This capacitance is calculated using plane capacitor formula. The inter-winding capacitance is neglected, due to the low copper thickness compared to the copper track length and width. The capacitance calculated for the EMI filter DM inductor is $442 \mathrm{pH}$ which results in a cut-off frequency close to $1.9 \mathrm{MHz}$, much higher than the frequency of the observed inductance drop. In addition, the routing of the test inductor (Fig. 4) is similar to a classic wire winding, with thin copper stripes (instead of the larger tracks visible, for example, in Fig. 4), which generate a much smaller parasitic capacitance. And yet, the inductance also drops earlier for the

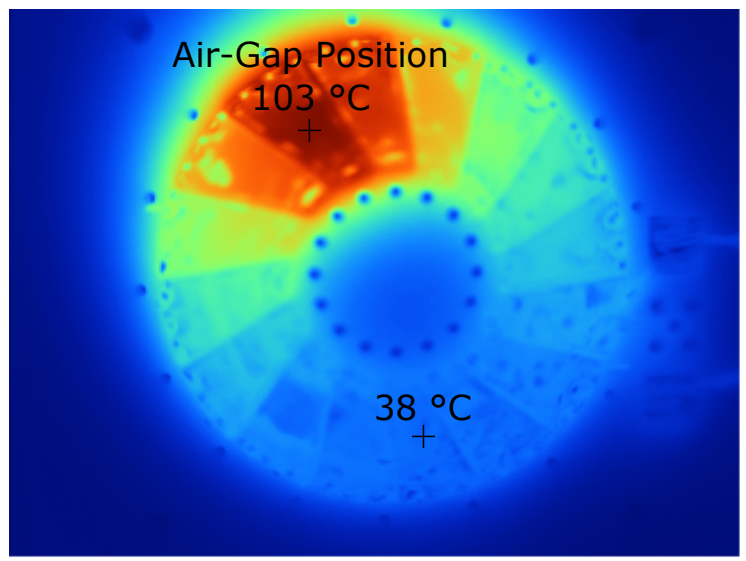

Fig. 9: Thermography of the DM inductor with a $20 \mathrm{kHz}, 14$ A peak-topeak current. The clear increase in temperature is attributed to eddy currents induced in the copper layer by the air-gap of the magnetic core.

core embedded in PCB with copper winding (yellow curve in Fig. 6). This means that this phenomenon is not caused by parasitic capacitance.

Another hypothesis was the presence of an undesired contact between the magnetic core and the winding, caused by a misalignment of vias. Vias drill through the core would create a secondary winding. The inductor would then act as a transformer with a secondary in short-circuit. In this case the inductance would decrease quickly with the frequency. To verify this, a hole was drilled in the PCB to get access to the surface of the magnetic core. A test with an ohmmeter and a visual inspection did not show any core/winding contact.

This high frequency behaviour is still under investigation. A possible explanation for the EMI filter DM inductor is a high increase in the $\mathrm{AC}$ resistance due to the presence of copper above the air-gap. In fact, a thermography of the EMI filter DM inductor is presented in Fig. 9. The inductance was supplied with a sinusoidal current at $20 \mathrm{kHz}, 14 \mathrm{~A}_{p p}$. A coating of photosensitive resin (Positiv 20, Kontakt Chemie, used because it can easily be removed) was sprayed on the inductor to obtain a uniform emissivity. A clear hot spot is visible $\left(103{ }^{\circ} \mathrm{C}\right.$ while at the opposite the temperature is $38{ }^{\circ} \mathrm{C}$ ). This hot spot can be associated with the presence of the air gap. However, it should be noted that no air-gap is present in the case of the test inductor, which also exhibits some reduction in the inductance at high frequency (see Fig. 6). The air-gap might not fully explain this phenomenon.

As described in Section II, it was found that the toroidal embedded structure offers the best trade-off between losses and box volume due to its good cooling capability. But as seen on the micro-section in Fig. 7, the magnetic core is hardly in contact with the PCB material: it is maintained only by a small amount of resin (see Fig. 7), and only lays on the bottom side of the cavity (from a thermal point-of-view, this is probably a poor contact). In the design procedure, it was assumed that the cavity was entirely filled with resin, resulting in much better thermal conductivity. A possible improvement would be to use more prepreg sheets (and prepreg sheets with a higher resin content) in the lamination process, so more resin would be 
available to flow and fill the cavity. However, more prepreg layers would contract more during the lamination; special care must then be given to prevent the cavity to shrink too much, as this would result in a contact between the magnetic core and the PCB laminates, and a non-uniform pressure distribution.

\section{CONCLUSION}

The toroidal embedded structure is attractive for large power magnetic components (inductors). Its manufacturing process relies on standard PCB technology, and allows to manufacture several inductors in a single process. The custom inductor geometry is automatically generated by the design program.

The lab-scale manufacturing process was detailed and used to produce several prototypes. A cavity is machined in PCB laminates to receive a magnetic core. As the cavity is slightly taller than the magnetic core, no pressure is transferred to the core during lamination. This prevents cracking this brittle material. However, this causes large parts of the cavity to remain empty, resulting in poor thermal exchange between the core and its environment. This might prove to be an issue and might require improvements of the manufacturing processes.

Demonstrators were made using Ni-Fe-Mo powder core and MnZn ferrite core. They show a good inductance behavior in the low frequency. But the inductance value decreases above a few tens of $\mathrm{kHz}$. This phenomena can be explained on the $\mathrm{MnZn}$ ferrite sample by the eddy currents induced in the copper layers by the magnetic field fringing from the large air-gap. However, for the Ni-Fe-Mo powder inductors, which have a distributed air gap, no explanation can currently be offered and this is still under investigation.

The design and manufacturing processes will now be optimized to take into account the fringing effect and the resin flow to improve thermal management. Future characterization will be performed in a calorimeter to accurately measure the losses in the inductor.

\section{REFERENCES}

[1] A. Ostmann, L. Boettcher, D. Manessis, S. Karaszkiewicz, and K.-D Lang, "Power modules with embedded components," in Microelectronics Packaging Conference (EMPC), 2013 European, Sep. 2013, pp. 1-4.

[2] J. Popovic-Gerber, "Passive Components Packaging," in ECPE Tutorial "Power Electronics Packaging", 2015, pp. 1-79.

[3] M. Ali, E. Labouré, F. Costa, and B. Revol, "Design of a Hybrid Integrated EMC Filter for a DC-DC Power Converter," IEEE Transactions on Power Electronics, vol. 27, no. 11, pp. 4380-4390, 2012.

[4] Q. Chen, Z. Gong, X. Yang, Z. Wang, and L. Zhang, "Design considerations for passive substrate with ferrite materials embedded in printed circuit board (pcb)," in 2007 IEEE Power Electronics Specialists Conference, June 2007, pp. 1043-1047.

[5] Y. Kondo, Y. Yazaki, M. Sonehara, T. Sato, T. Watanabe, Y. Seino, N. Matsushita, T. Fujii, K. Kobayashi, H. Shimizu et al., "Embedded planar power inductor technology for package-level DC power grid," in Electronics Packaging and iMAPS All Asia Conference (ICEP-IACC), 2015 International Conference on. IEEE, 2015, pp. 814-817.

[6] A. Alderman, L. Burgyan, B. Narveson, and E. Parker, "3-D Embedded Packaging Technology.” IEEE Power Electronics Magazine, pp. 30-39, 2015.

[7] D. Bang and J. Park, "Ni-Zn ferrite screen printed power inductors for compact dc-dc power converter applications." IEEE Transactions on Magnetics, vol. 45, no. 6, pp. 2762-2765, 2009.

[8] R. Caillaud, C. Buttay, J. Le Lesle, F. Morel, R. Mrad, N. Degrenne, S. Mollov, and C. Combettes, "High power PCBembedded inductors based on ferrite powder." [Online]. Available: https://hal.archives-ouvertes.fr/hal-01535727

[9] C. Marxgut, J. Muhlethaler, F. Krismer, and J. W. Kolar, "Multiobjective optimization of ultraflat magnetic components with pcb-integrated core," IEEE Transactions on Power Electronics, vol. 28, no. 7, pp. 3591-3602, 2013.

[10] R. Caillaud, C. Buttay, R. Mrad, J. Le Lesle, F. Morel, N. Degrenne, and S. Mollov, "Comparison of planar and Toroidal PCB integrated inductors for a multi-cellular $3.3 \mathrm{~kW}$ PFC." in IEEE International Workshop On Integrated Power Packaging (IWIPP), 2017.

[11] A. Balakrishnan, W. T. Joines, S. Member, T. G. Wilson, and L. Fellow, "Air-Gap Reluctance and Inductance Calculations for Magnetic Circuits Using a Schwarz - Christoffel Transformation," IEEE Transactions on Power Electronic, vol. 12, no. 4, pp. 654-663, 1997. 